\title{
A New Switched Flux Machine Employing Alternate Circumferential and Radial Flux (AlCiRaF) Permanent Magnet for Light Weight EV
}

\author{
Mahyuzie Jenal $^{1 *}$, Erwan Sulaiman ${ }^{1}$, and Rajesh Kumar ${ }^{1}$ \\ ${ }^{1}$ Research Center for Applied Electromagnetics, Universiti Tun Hussein Onn Malaysia, 86400 Batu Pahat, Johor, Malaysia
}

(Received 9 June 2016, Received in final form 11 November 2016, Accepted 6 December 2016)

\begin{abstract}
Currently, an interest in electric vehicles (EVs) exhibited by automakers, government agencies and customers make it as more attractive research. This is due to carbon dioxide emitted by conventional combustion engine that worsens the greenhouse effect nowadays. Since electric motors are the core of EVs, it is a pressing need for researchers to develop advanced electric motors. As one of the candidates, switched flux machine (SFM) is initiated in order to cope with the requirement. This paper proposes a new alternate circumferential and radial flux (AlCiRaF) of permanent magnet switched flux machines (PMSFM) for light weight electric vehicles. Firstly, AlCiRaF PMSFM is compared with the conventional PMSFM based on some design restrictions and specifications. Then the design refinements techniques are conducted by using deterministic optimization method in order to improve preliminary performance of machine. Finally the optimized machine design has achieved maximum torque and power of $47.43 \mathrm{Nm}$ and $12.85 \mathrm{~kW}$, respectively, slightly better than that of conventional PMSFM.
\end{abstract}

Keywords : brushless machine, electric vehicles, optimization, permanent magnet, switched flux machine

\section{Introduction}

In recent decades, global warming becomes major concern in society. As a result, many extensive studies have been carried out by different parties to come out with series of factor findings, promising proposals and feasible solutions [1-5]. As reported in [1, 2], one of the major factors in worsening the global warming is the emission of man-made greenhouse gases [GHGs], especially carbon dioxide $\left(\mathrm{CO}_{2}\right)$, is classified as one of the major GHGs released into the atmosphere by combustion of fossil fuel [3]. Apparently for more than 100 years, conventional internal combustion engine (ICE) has been utilized in vehicles for personal transportation which undisputedly, contribute to increased emissions of $\mathrm{CO}_{2}$. Currently, demands for private vehicles are increasing due to the rapid rising rate of world population $[4,5]$. Consequently, the government and related agencies have introduced more stiff standards to restrain the setback of emissions and fuel efficiency. On the other hand, in order to obtain a wide-range of full-performance and high

CThe Korean Magnetics Society. All rights reserved.

*Corresponding author: Tel: +0197648488

Fax:+60-07-453-6060, e-mail: mahyuzie@uthm.edu.my efficiency vehicle while eliminating pollutant emissions, the most feasible solution at present is electric vehicle (EV) which are driven by battery-based electric motor [68]. Since electric motor is the key of an EV, SFM has recently become a well known and attractive design of machine type due to their numerous advantages such as low level of vibration and acoustic noise, high torque density and efficiency [7-11].

In 1955, PMSFM was preliminary introduced as a singlephase alternator by Rauch and Johnson [12] and has been receiving significant attention afterwards especially in electric propulsion system application. Meanwhile, the first three-phase system was developed in 1997 by E. Hoang et al. [13]. The conventional design as shown in Fig. 1(a) is however, inherit the disadvantage of high PM volume. Hence, variety of PMSFM designs has been reported since then. In order to reduce the consumption of PM, the stator poles are replaced alternately by a simple stator tooth and therefore the new E-core is developed [14]. The stator core is then merged together to form ECore PMSFM stator and half of the PM volume in [13] is removed. The E-Core configuration is also recorded in [15] with combination arrangement between horizontal and vertical of low-coercive force (LCF) magnets. The horizontal magnets are alternately attached to the stator 
teeth tips and the vertical magnets remain identical as the conventional design. Moreover, the middle E-stator teeth can be removed to enlarge the slot area and consequently the new C-core PMSFM is introduced [16]. Another class of PMSFM applying segmental rotor has been published in [17] but its rotor structure has cause doubtful and nonrobust operation while rotating at high speed. On top of these topologies, the main constraints are magnetic flux leakage at the utmost tips of PM which limits the distribution of flux and also their separated stator from one segment to another that is hardly to manufacture and assemble.

This paper presents an extensive study on a new 6Slot10Pole PMSFM employing alternate circumferential and radial flux PM. Initially, the feasibility study of proposed machine has been discussed and investigated in $[18,19]$. The suggested machine design consists of significant single piece stator with iron-bridge to prevent any flux leakage flow out of the laminated stator core. However, based on initial analysis using finite element analysis (FEA), the proposed machines have several drawbacks that prevent the machine to achieve maximum performances especially at maximum current densities compared to the conventional PMSFM. Therefore, to improve the design drawbacks, some design refinements and optimization are conducted using deterministic optimization approach [20, 21].

The examination on initial design machine based on 2D-FEA of 6S-10P AlCiRaf PMSFM is discussed in Section II. The approach of obtaining maximum performances based on FEA is explained in Section III. The optimized topology and optimal performances of the machine are analyzed in Section IV. Finally, Section V draws some comprehensive conclusions of the thorough investigation.

\section{FEA-Based Analysis On 6S-10P AlCiRaF PMSFM}

\subsection{Design Restrictions and Specifications}

6S-10P AlCiRaF PMSFM with wound salient rotor structure is illustrated in Fig. 1(b). Initial design is developed using commercial FEA package, JMAGDesigner V. 14 software whereas 2D finite element solver is applied for the rest of studies. Fig. 1(b) illustrates 12 stator teeth, 6 armature coil slots or slots for phase windings, 10 salient rotor poles and 12 pieces of permanent magnets which consist of alternate radial and circumference flux direction. The stator is having slots/grooves bearing the phase windings which are 6 armature coils wounded in between 12 grooves/slots fabricated in the stator. The PMs are arranged in radial and circumference

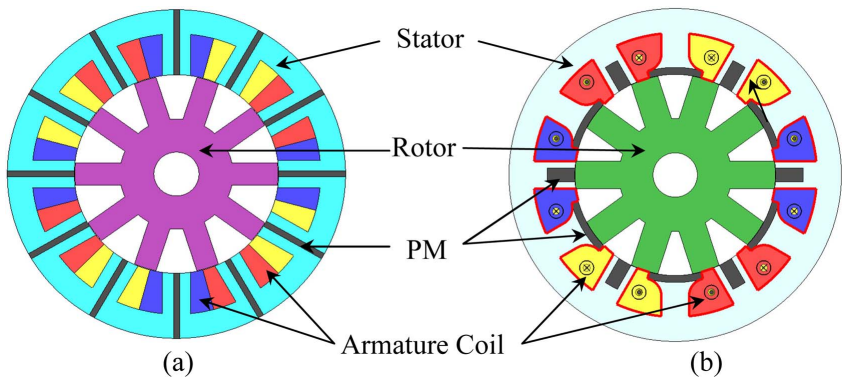

Fig. 1. (Color online) PMSFM machine design (a) Conventional (b) Initial AlCiRaF.

flux direction, respectively. The total volume of PM is set to maximum $0.5 \mathrm{~kg}$ for optimum performances. The material type used is Neomax $35 \mathrm{AH}$ which having coercive force at $20^{\circ} \mathrm{C}$ and residual flux density of $932 \mathrm{kA} / \mathrm{m}$ and $1.2 \mathrm{~T}$, while for the rotor and stator parts are made up of electrical steel $35 \mathrm{H} 210$. The fundamental rotor structure is mechanically robust to spin at high speed because it consists of only laminated electromagnetic sheets.

Furthermore, active components such as phase windings and PM are located on the stator core in order to provide a simple cooling system to dissipate heat from the body. The three-phase armature coils are accommodated on each of the stator body periodically while the directions of the windings are in counter-clockwise along with clockwise polarity. With single piece of 10 pole iron rotor, the machine is extremely robust and suitable for high speed application especially for electric vehicle. In addition, the PM in stator generates the excitation flux that reacts with armature flux. The AlCiRaF PMSFM is suitable for high speed electric vehicle applications due to robust rotor structure and has high efficiency and less copper loss due to all active parts located on the stator

Table 1. Parameters specifications of initial 6S-10P AlCiRaF PMSFM.

\begin{tabular}{lcc}
\hline \hline \multicolumn{1}{c}{ Parameter } & Conventional & AlCiRaF \\
\hline No. of phase & 3 & 3 \\
Max. DC-bus voltage inverter $(\mathrm{V})$ & 415 & 415 \\
Max. inverter current $\left(\mathrm{A}_{\mathrm{rms}}\right)$ & 45 & 45 \\
Max. current density in armature winding, $\mathrm{J}_{\mathrm{a}}$ & 30 & 30 \\
No. of slot & 12 & 6 \\
No. of rotor pole & 10 & 10 \\
Outside diameter of stator $(\mathrm{mm})$ & 150 & 150 \\
Motor stack length $(\mathrm{mm})$ & 70 & 70 \\
Length of air gap $(\mathrm{mm})$ & 0.3 & 0.3 \\
Armature slot area $\left(\mathrm{mm}^{2}\right)$ & 150.4 & 300.8 \\
No. of turns per armature coil slot & 22 & 44 \\
PM volume $(\mathrm{kg})$ & 0.5 & 0.5 \\
\hline
\end{tabular}


with concentrated type of winding configuration.

In this study, the possible number of rotor pole and stator slot combination is defined by (1).

$$
N_{r}=N_{s}\left(1 \pm \frac{k}{2 q}\right)
$$

where $N_{r}$ is the number of rotor poles, $N_{s}$ is the number of stator slots, $k$ is the natural entity having value $1,2,3, \ldots$ and $q$ is the number of phases. Supposing that only a water-jacket system is applied as the cooling system of the machine where value of $30 \mathrm{~A}_{\mathrm{rms}} / \mathrm{mm}^{2}$ is set to be the limit of the armature current density and the relationship can be determined by (2)

$$
J_{a}=\frac{I_{a} N_{a}}{\alpha_{a} s_{a}}
$$

where $J, N, \alpha, S$ and $I$ are current density, number of turns, filling factor, slot area and input current, respectively while subscript $a$ represents armature coil. Beside this, the electrical frequency, $f_{e}$ of the proposed motors can be expressed by (3)

$$
f_{e}=N_{r} \cdot f_{m}
$$

where $f_{e}$ is the electrical frequency, $f_{m}$ is the mechanical rotation frequency and $N_{r}$ is the number of rotor poles. On the other hand, Table 1 shows design specifications of the proposed machine.

\subsection{Initial Performances of the Proposed Machines}

Figure 2 demonstrates simulated results of the initial and conventional machine as they have been examined under the load condition along with the variation of armature current density, $\mathrm{J}_{\mathrm{a}}$. The resulting simulation interprets that as $\mathrm{J}_{\mathrm{a}}$ is increased from 0 to $30 \mathrm{~A} / \mathrm{mm}^{2}$, the initial output torque of the machine is consistently increasing as well and peaks at maximum value of 25.54 $\mathrm{Nm}$. However, rising profile of output power only take place for the first $50 \%$ of maximum $\mathrm{J}_{\mathrm{a}}$ before it shows early saturated peak measured approximately at $5 \mathrm{~kW}$. On the other hand, conventional machine design displays better result with maximum average torque of $44.11 \mathrm{Nm}$ [18] while power profile demonstrates its decaying pattern as $\mathrm{J}_{\mathrm{a}}$ rises from $10 \mathrm{~A}_{\mathrm{rms}} / \mathrm{mm}^{2}$ up to $30 \mathrm{~A}_{\mathrm{rms}} / \mathrm{mm}^{2}$. This is affected by the slowing down speed of machine as it suffers iron and copper losses. Apparently, conventional design comprises 12 coils of armature winding compared to only 6 of them employed in AlCiRaF which result in higher copper losses as well as longer coil length. Significantly, the initial proposed machine is required to go through design refinement in order to obtain better performance compare to that of conventional machine.

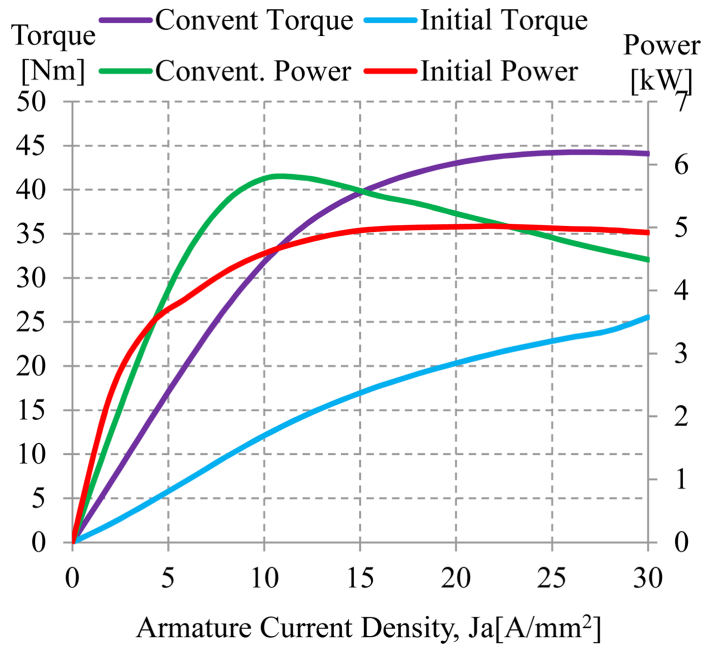

Fig. 2. (Color online) Initial torque and power versus various $\mathrm{J}_{\mathrm{a}}$.

\section{Machine Optimization Approach}

In realizing the weak performances of proposed machine that has been compared with conventional design and its potential ability to achieve even better performances, therefore optimization is carried out, so the optimal torque and power can be obtained accordingly. As a result, Fig. 3 illustrates certain design parameters commenced on both stator and rotor part. Commonly, the design parameters are segregated into three groups namely rotor core, PM shape and armature coil slot. Subsequently, PM is then broken down into another two sub-groups which are PM1 as well as PM2 wherein PM1 is particularly assigned for magnetic flux in radial order whereas PM2 is for circumferential magnetic flux profile. Pertaining to the figure, all rotor parameters are labelled as L1, L2 and L3, while L4 and L5 are assigned to PM1, L6 and L7 are meant for PM2. Finally, armature coil slots are defined by parameter of L8 and L9.

The optimization procedure begins by updating rotor parameters L1, L2 and L3 individually while L4 up to L9 are kept constant. Significantly, rotor radius, L1 is treated at the first place in a sense to compute the optimal combination between torque and power capability. The finest L1 result is then carried forward and constantly unchanged while treating rotor pole width, L2. Similarly, the finest L2 result will be kept as the rotor pole depth, L3 is undergoing optimization process. On top of that, the air gap size of $0.3 \mathrm{~mm}$ is kept unchanged till end of progression. Consequently, the identical methodology is implemented in the following stage which engages PM width and depth. The most decisive part is to keep PM volume of $0.5 \mathrm{~kg}$ unchanged while treating L4, L5, L6 and L7 
respectively by ensuring the rest of design parameters are constant. Additionally, the pole shoe shape of stator tooth remains unvaried while varying PM1, regardless the dimension of L4 and L5. With the optimal output achieved in second stage, armature coil slot parameters, L8 and L9 are then updated in final stage to figure out further fined combination result in form of torque and power performances.

At the beginning steps in which L1 up to L9 are updated, the armature slot area of $300.8 \mathrm{~mm}^{2}$ has been kept constant prior to have the same number of armature winding. However, after all the parameters optimization have been done, the slot area and number of turn are also varies as well, in order to obtain better optimal torque further achievement. Apparently, the pole shoe shape of stator tooth is eventually eliminated and leaves the armature slot to form a solid trapezoidal shape. This is to guarantee that magnetic flux flow smoothly and simultaneously which would avoid from the occurrence of flux saturation at both side of pole shoe edge tips.

\section{Optimized Design and Performance Analysis}

\subsection{Configuration of Optimized Design}

The topologies of conventional, initial and optimized design machines are portrayed in Fig. 4(a), Fig. 4(b) and Fig. 4(c) respectively while the comparison between initial and optimized design parameters are listed in Table 2. Obviously, by comparing between Fig. 4(b) and Fig. 4(c), the pole shoe structure of stator teeth has been abolished, leaving them in straight formation as spotted in red circles. On top of that, Fig. 5(b) shall signify better flux distribution and linkage in between stator and rotor part as it may reduce the flux saturation at both sides of shoe pole edges for initial design as marked in black circles. Moreover, the flux distribution in particular stator is much better and a thorough circulation can be observed

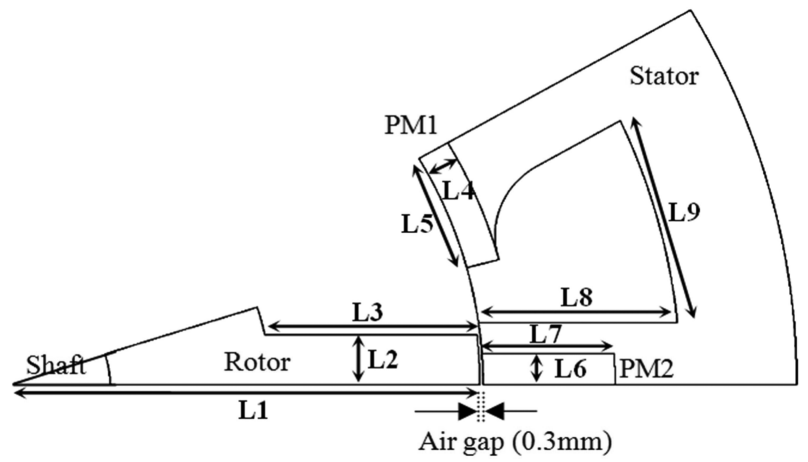

Fig. 3. Design parameters of initial 6S-10P AlCiRaF PMSFM.
Table 2. Initial and optimization design parameters.

\begin{tabular}{llcc}
\hline \hline & \multicolumn{1}{c}{ Description } & Initial & Optimized \\
\hline L1 & Rotor radius (mm) & 45 & 55 \\
L2 & Rotor pole width (mm) & 6.25 & 5 \\
L3 & Rotor pole depth (mm) & 20 & 25 \\
L4 & PM1 depth (mm) & 3.15 & 2.15 \\
L5 & PM1 width (mm) & 11.83 & 6.25 \\
L6 & PM2 width (mm) & 3.155 & 3.49 \\
L7 & PM2 depth (mm) & 12.5 & 18.74 \\
L8 & Armature coil slot depth (mm) & 18.7 & 14.8 \\
L9 & Armature coil slot width (mm) & 20.9 & 24.2 \\
$\mathrm{~N}_{\mathrm{a}}$ & No. of turn armature coil & 44 & 42 \\
$\mathrm{~S}_{\mathrm{a}}$ & Armature slot area $\left(\mathrm{mm}^{2}\right)$ & 300.8 & 287 \\
\hline
\end{tabular}

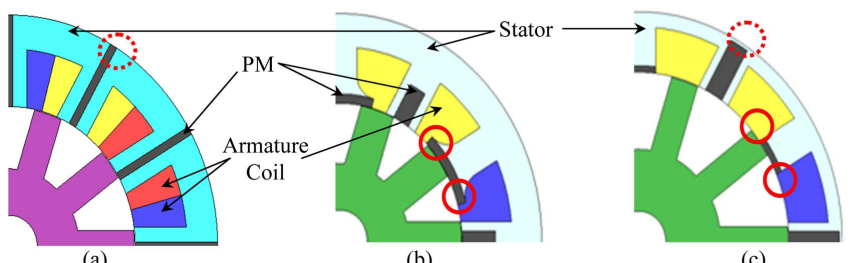

Fig. 4. (Color online) Topology comparison of (a) Conventional machine (b) Initial AlCiRaF machine (c) Optimized AlCiRaF machine.

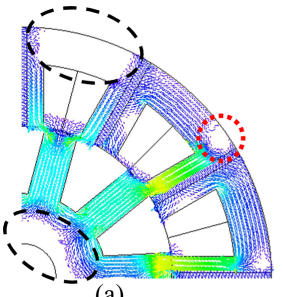

(a)

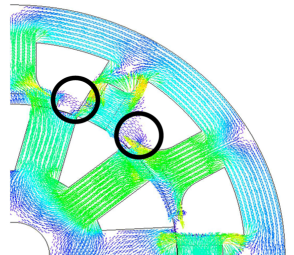

(b)

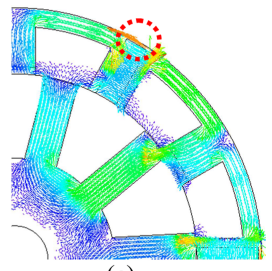

(c)
Fig. 5. (Color online) Magnetic flux distribution of (a) Conventional machine (b) Initial AlCiRaF machine (c) Optimized AlCiRaF machine.

rather than empty fluxed stator detected in the conventional design and this phenomenon is highlighted in dark dotted circle of Fig. 5(a).

In addition, less flux distribution is also highlighted at rotor core due to the circumferential configuration of PMs in the conventional design which limits the distribution of magnetic fluxes throughout the machine. In contrast, the alternate radial configuration of PMs in AlCiRaF design has result in the magnetic fluxes to flow to the entire stator core and generate a direct path to rotor core and the other way around. Besides, higher flux concentration accumulated in rotor poles after design optimization has cause better ability for machine to rotate at high speed. Additionally, the larger rotor diameter will generate higher power capability. After all, iron bridge structure proposed 


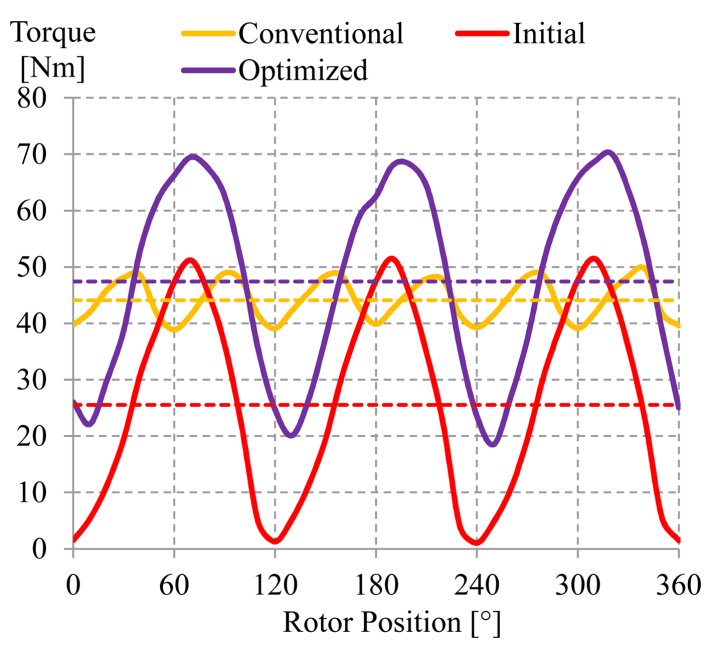

Fig. 6. (Color online) Instantaneous torque characteristics.

in AlCiRaF design has a better capability to avoid any flux leakages unlike the conventional design. Comparisons of these structures are shown in red dotted circles.

\subsection{Instantaneous Torque}

Figure 6 depicts the instantaneous torque profiles over the rotor's mechanical rotation in degree of the machines under study. Notably, optimized design contributes the highest torque of approximately $70.11 \mathrm{Nm}$ even though having a larger peak to peak range compared with the conventional machine. As for comparison, the peak to peak value of the conventional machine is five times better than that of optimized machine.

\subsection{Torque and Power versus Armature Current Den-} sity, $\mathbf{J}_{\mathbf{a}}$

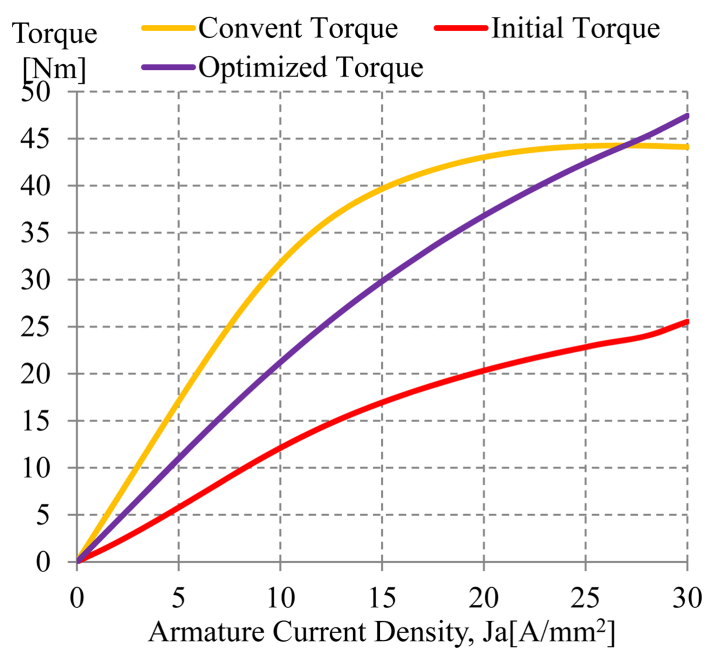

Fig. 7. (Color online) Torque versus armature current density, $J_{a}$ characteristics.

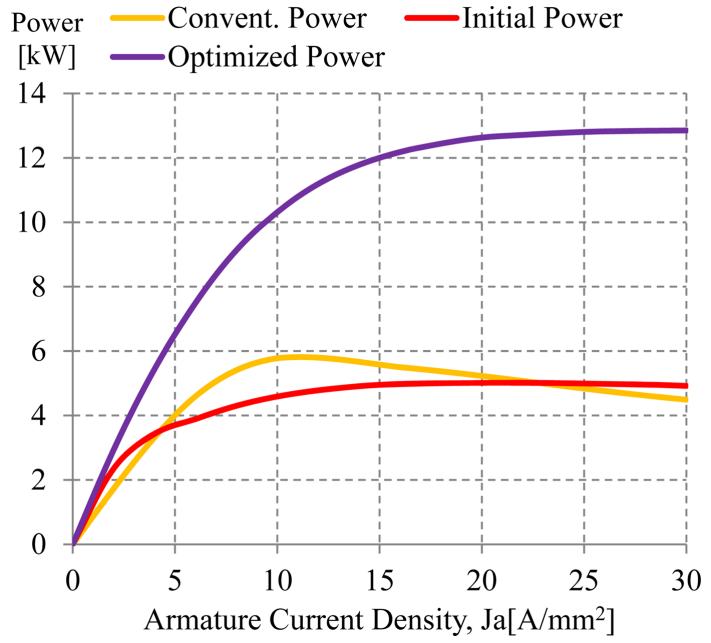

Fig. 8. (Color online) Power versus armature current density, $\mathrm{J}_{\mathrm{a}}$ characteristics.

The torque and power generation of the machines at various armature current densities are also investigated. Under this study, the armature current density is varied from $0 \mathrm{~A} / \mathrm{mm}^{2}$ up to $30 \mathrm{~A} / \mathrm{mm}^{2}$ while the resulting data of torque and power characteristics are plotted in Fig. 7 and Fig. 8, respectively. It is comprehensible that an increase in armature current density will relatively enhance the torque and power performances except for the conventional design which the maximum power is produced at $\mathrm{J}_{\mathrm{a}}$ of $10 \mathrm{~A} / \mathrm{mm}^{2}$. Thus, a maximum torque of $47.43 \mathrm{Nm}$ and power of $12.85 \mathrm{~kW}$ are achieved at maximum armature current density, $30 \mathrm{~A} / \mathrm{mm}^{2}$. Apparently, the torque performance is $7.5 \%$ and $85.71 \%$ better than that of conventional and initial design machine, respectively. Meanwhile, for power progression, the optimized design computes the highest result of $12.85 \mathrm{~kW}$.

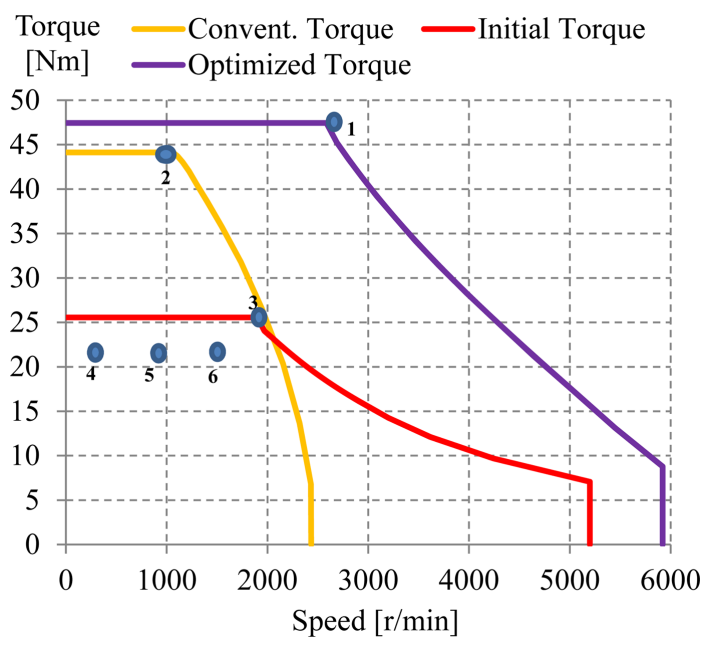

Fig. 9. (Color online) Torque versus speed characteristics. 


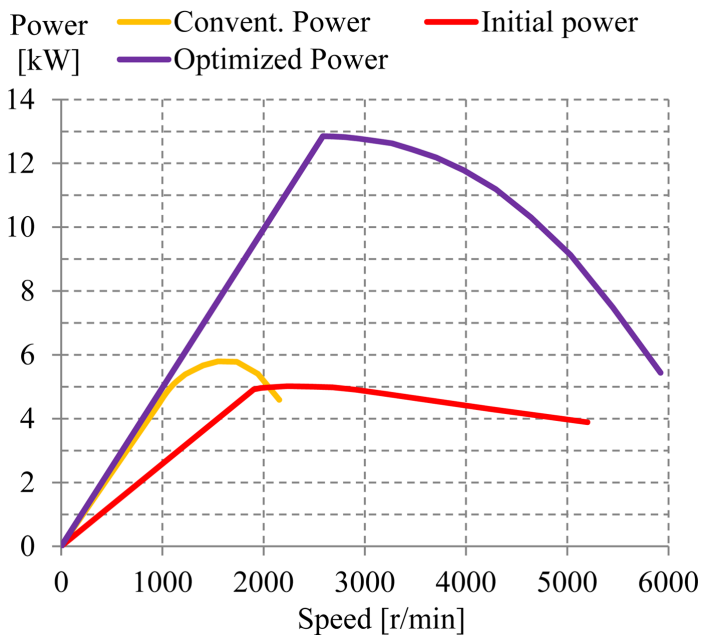

Fig. 10. (Color online) Power versus speed characteristics.

\subsection{Torque and Power versus Speed Characteristics}

Figure 9 addresses the profile of torque against speed for conventional, initial and optimized machine design while Fig. 10 demonstrates the plotted graph of power for the same motor designs. According to Fig. 9, the undisputed differences can be digested between all machines that optimized design machine again emerges with maximum average torque of $47.43 \mathrm{Nm}$, gauged at the base speed of $2586 \mathrm{r} / \mathrm{min}$, improving the target torque of conventional design machine which is $44.11 \mathrm{Nm}$ at base speed of 973 $\mathrm{r} /$ min whilst the corresponding power in Fig. 10 reaches approximately $12.85 \mathrm{~kW}, 156 \%$ enormous gain compared with initial performance. In general, power profiles depicted in Fig. 10 suffers significant losses as the machine speed is increased. This is caused by copper losses that dissipated as heat in the armature windings, because these windings have some internal resistance in them. More- over, hysteresis loss and eddy current loss both depend upon magnetic properties of the materials used to construct the core of machine and its design. So these losses in machine are alternatively known as iron loss. On the other hand, speed progression for both initial and optimized designs depict less significant different unless for lower speed range of the conventional design.

\subsection{Power Loss and Efficiency}

Calculation based on finite element analysis is utilized to find out the motor loss and efficiency considering copper losses in armature coil and iron losses in all laminated cores. Fig. 9 again exhibits the torque versus speed characteristics of conventional, initial and optimized design machines, respectively with specific operating points at maximum torque and frequent operating point under light load that labeled as No. 1 to No. 6. Meanwhile, the detail loss analysis and motor efficiency of the designed machines are summarized in Table 3 accordingly. In particular, point 1 , point 2 and point 3 are the maximum operating torque of each machine whereas point 4 up to point 6 fall under the similar average operating region of all machines.

At each machine's base speed where maximum torque is achieved, optimized machine appears to be the highest efficiency with $96.96 \%$ although it has the most copper loss, followed by conventional and initial machine with respective $93.24 \%$ and $92.7 \%$ performances. On the other hand, while running at the average operating points, the maximum efficiency is obtained for conventional design at point 6 with result of $99.43 \%$. It is notable that the conventional machine's maximum speed is only about $2453 \mathrm{r} / \mathrm{min}$ that cause the efficiency does not degrade as much as the optimized machine does. Nevertheless, the

Table 3. Loss and efficiency.

\begin{tabular}{|c|c|c|c|c|c|c|}
\hline $\begin{array}{l}\text { Machine } \\
\text { Designs }\end{array}$ & $\begin{array}{l}\text { Operat. } \\
\text { Points }\end{array}$ & $\begin{array}{c}\text { Speed } \\
(\mathrm{r} / \mathrm{min})\end{array}$ & $\begin{array}{c}\text { Output Power } \\
(\mathrm{kW})\end{array}$ & $\begin{array}{c}\text { Iron Loss } \\
(\mathrm{kW})\end{array}$ & $\begin{array}{c}\text { Copper Loss } \\
(\mathrm{kW})\end{array}$ & $\begin{array}{l}\text { Eff. } \\
(\%)\end{array}$ \\
\hline \multirow{4}{*}{ Conventional } & 2 & 973 & 42.92 & 0.336 & 2.78 & 93.24 \\
\hline & 4 & 500 & 10.18 & 0.072 & 0.11 & 98.23 \\
\hline & 5 & 1000 & 20.36 & 0.043 & 0.11 & 99.25 \\
\hline & 6 & 1500 & 30.54 & 0.064 & 0.11 & 99.43 \\
\hline \multirow{4}{*}{ Initial } & 3 & 1902 & 48.58 & 0.935 & 2.89 & 92.7 \\
\hline & 4 & 500 & 10.72 & 0.166 & 1.56 & 86.17 \\
\hline & 5 & 1000 & 21.44 & 0.252 & 1.56 & 92.23 \\
\hline & 6 & 1500 & 32.16 & 0.529 & 1.56 & 93.91 \\
\hline \multirow{4}{*}{ Optimized } & 1 & 2586 & 122.65 & 0.846 & 3.00 & 96.96 \\
\hline & 4 & 500 & 10.61 & 0.064 & 0.33 & 96.39 \\
\hline & 5 & 1000 & 21.22 & 0.078 & 0.33 & 98.10 \\
\hline & 6 & 1500 & 31.83 & 0.246 & 0.33 & 98.21 \\
\hline
\end{tabular}


Table 4. Overall performances comparison.

\begin{tabular}{lccc}
\hline \hline \multicolumn{1}{c}{ Items } & Conventional & Initial & Optimized \\
\hline Max. speed (r/min) & 2432 & 5200 & 5912 \\
Power $(\mathrm{kW})$ & 5.79 & 5.02 & 12.85 \\
Torque $(\mathrm{Nm})$ & 44.11 & 25.54 & 47.43 \\
Output power $(\mathrm{kW})$ & 104 & 112.9 & 186.31 \\
Iron losses $(\mathrm{kW})$ & 0.515 & 1.88 & 1.23 \\
Copper losses $(\mathrm{kW})$ & 3.11 & 7.57 & 3.99 \\
Efficiency $(\%)$ & 96.63 & 92.28 & 97.27 \\
\hline
\end{tabular}

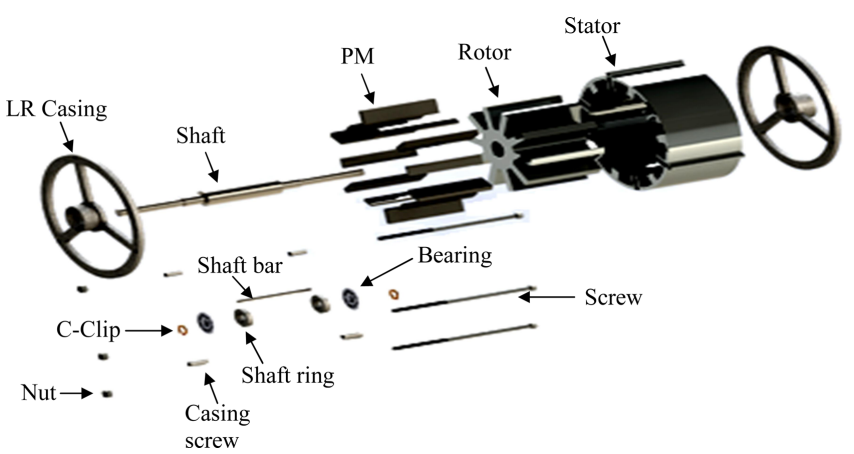

Fig. 11. (Color online) The 3D-exploded view of optimized 6S-10P AlCiRaF PMSFM.

maximum average efficiency of the machine goes to the optimized design with $97.27 \%$. The overall performances of the proposed machines are summarized in Table 4 while Fig. 11 demonstrates the entire 3D-exploded view of the optimized AlCiRaF machine.

\section{Conclusion}

This paper has presented the newly proposed design and performance study of 6Slot-10pole AlCiRaf PMSFM for light weight EV. The design refinement procedure to achieve the target performance has been clearly described. As a result, the proposed machine has better torque, power, speed ranges and efficiency compared with conventional 12Slot-10Pole PMSFM. Finally, the optimized machine design has improved approximately $85.71 \%$ of maximum torque and $156 \%$ of maximum power than that of initial machine design. With all the analytical study, the proposed AlCiRaF PMFSM will distinctly grant the best outcome when tested with a prototype model as compared with the previous work that has been done by many researchers.

\section{Acknowledgement}

This work was funded by Product Development Grant
(B063), Universiti Tun Hussein Onn Malaysia (UTHM) and Ministry of Education Malaysia (MOE).

\section{References}

[1] B. K. Bose, IEEE Industrial Electronics Magazine 4, 6 (2010).

[2] W. Mills, K. Heidel, and C. F. Chung, IEEE EIC Climate Change Technology (ON), (2006) pp. 1-10.

[3] Harinandan Kumar and S. Ravikumar, Recent Advances in Space Technology Services and Climate Change (RSTSCC), (2010) pp. 364-371.

[4] S. Pal, 1st International Conference on the Developments in Renewable Energy Technology (ICDRET), (2009) pp. $1-3$.

[5] B. R. Singh and O. Singh, 3rd International Conference on Thermal Issues in Emerging Technologies Theory and Applications (ThETA), (2010) pp. 323-329.

[6] H. Ribberink and E. Entchev, World Electric Vehicle Symposium and Exhibition (EVS27), (2013) pp. 1-7.

[7] E. B. Sulaiman, T. Kosaka and N. Matsui, XXth International Conference on Electrical Machines (ICEM), (2012) pp. 1269-1275.

[8] W. Fei, P. C. K. Luk, J. Shen, and Y. Wang, 3rd International Conference on Power Electronics Systems and Applications (PESA), (2009) pp. 1-6.

[9] W. Hua, M. Cheng, Z. Q. Zhu, and D. Howe, IEEE Trans. Energy Conversion 23, 727 (2008).

[10] D. Wang, X. Wang, and S.-Y. Jung, J. Magn. 18, 361 (2013).

[11] M. Z. Ahmad, E. Sulaiman, M. Jenal, W. M. Utomo, S. A. Zulkifli, and A. A. Bakar, IEEE Conf. on Clean Energy \& Technology (CEAT), (2013).

[12] S. E. Rauch and L. J. Johnson, Design principles of flux switching alternators, AIEE Trans. 74III, 1261 (1955).

[13] E. Hoang, A. H. Ben-Ahmed, and J. Lucidarme, 7th Eur. Conf. Power Electron. Appl. 13, 903 (1997).

[14] J. T. Chen, Z. Q. Zhu, S. Iwasaki, and R. Deodhar, IEEE Energy Conversion Congress and Exposition (2010).

[15] H. Yang, H. Lin, Z. Q. Zhu, S. Fang, and Y. Huang, IEEE Trans. Magn. 51, 11 (2015).

[16] J. T. Chen, Z. Q. Zhu, S. Iwasaki, and R. Deodhar, XIX Int. Conf. on Elec. Machines (ICEM), (2010).

[17] A. Zulu, B. C. Mecrow, and M. Armstrong, IEEE Trans. Ind. Appl. 48, 2259 (2012).

[18] M. Jenal and E. Sulaiman, ARPN J. Eng. Appl. Sci. 10, 6513 (2015).

[19] M. Jenal and E. Sulaiman, ARPN J. Eng. Appl. Sci. 10, 8846 (2015).

[20] E. Sulaiman, M. Z. Ahmad, T. Kosaka, and N. Matsui, Procedia Eng. 53, 312 (2013).

[21] M. Z. Ahmad, E. Sulaiman, and T. Kosaka, J. Magn. 20, 265 (2015). 